\title{
Review Article \\ Herbal Medicines for Asthmatic Inflammation: From Basic Researches to Clinical Applications
}

\author{
Fang Liu, ${ }^{1}$ Nan-Xia Xuan, ${ }^{1}$ Song-Min Ying, ${ }^{1}$ Wen Li, ${ }^{1}$ Zhi-Hua Chen, ${ }^{1}$ and Hua-Hao Shen ${ }^{1,2}$ \\ ${ }^{1}$ Department of Respiratory and Critical Care Medicine, Second Affiliated Hospital, Zhejiang University School of Medicine, \\ Hangzhou 310009, China \\ ${ }^{2}$ State Key Laboratory of Respiratory Diseases, Guangzhou 510120, China
}

Correspondence should be addressed to Zhi-Hua Chen; zhihuachen@zju.edu.cn and Hua-Hao Shen; huahaoshen@zju.edu.cn

Received 18 March 2016; Revised 22 May 2016; Accepted 5 June 2016

Academic Editor: Seong-Gyu Ko

Copyright (C) 2016 Fang Liu et al. This is an open access article distributed under the Creative Commons Attribution License, which permits unrestricted use, distribution, and reproduction in any medium, provided the original work is properly cited.

\begin{abstract}
Asthma is one of the most common chronic inflammatory disorders, associated with reversible airflow obstruction, airway hyperresponsiveness, and airway remodeling. This disease has a significant impact on individuals, their families, and society. Standardized therapeutics such as inhaled corticosteroid in combination with long acting $\beta 2$ agonist have been applied for asthma control; however, complementary and alternative medicines, especially herbal medicines, are still widely used all over the world. A growing body of literature suggests that various herbals or related products might be effective in inhibiting asthmatic inflammation. In this review, we summarize recent advances about the mechanistic studies of herbal medicines on allergic airway inflammation in animal models and their potential application into clinic for asthma control.
\end{abstract}

\section{Introduction}

Asthma is a chronic inflammatory disease characterized by reversible airway obstruction, airway hyperresponsiveness (AHR), infiltration of inflammatory cells, mucus hypersecretion, and airway remodeling [1]. It affects 300 million individuals worldwide, with the prevalence ranging from $1 \%$ to $18 \%$ of the population in different countries [2]. A variety of immune cells, structure cells in the lung, cytokines, chemokines, adhesion molecules, and signaling pathways contributes to the asthmatic pathogenesis. Although standardized therapeutics such as inhaled corticosteroid (ICS) in combination with long acting $\beta 2$ agonist (LABA) have been used to control asthma symptoms, complementary and alternative medicine (CAM) is still common all over the world. A survey involved 7685 individuals aged 55 or older with current asthma was performed recently in USA, and it showed that CAM use in the older adult asthmatic population was frequent, with nearly $40 \%$ using some type of CAM [3]. Another survey about traditional Chinese medicine (TCM) for pediatric asthma in Taiwan showed that $57.95 \%(N=26585)$ of the investigated children had used TCM [4].
Based on the facts that TCM or CAM is widely used in asthma control, increasing basic or clinical studies have been conducted to investigate the molecular mechanisms or clinical applications of herbal medicines for asthma therapy. Given the fact that asthma pathogenesis is complex, the roles and effective targets of these herbal products in asthma therapy are also very complicated.

In general, basic researches are all trying to separate effective monomer from herbs or herbal formula for asthma study, while most clinical researches still only focus on the efficacy for patients using an intact traditional formula. We will illuminate the major achievements of them, respectively, in this review.

\section{Basic Researches}

Basic researches on herbal asthma therapy can be summarized into nine aspects according to the mechanism summarized below. Those researches that only reported some $\mathrm{T}$ helper 1 (Th1) cell or T helper 2 (Th2) cell cytokines, for example, Interleukin-4 (IL-4), IL-5, IL-13, and interferon- $\gamma$ (IFN- $\gamma)$, altered after herbs intervention without any further 
mechanistic studies will not be expatiated in our paper, as they can be affected by many factors.

2.1. Targeting the Th1/Th2 Imbalance. It is generally accepted that $T h 1 / T h 2$ imbalance is responsible for the development of allergic asthma. Th1 cells secrete IFN- $\gamma$, IL-12, and tumor necrosis factor- $\beta$ (TNF- $\beta$ ), whereas Th 2 cells secrete IL- 4 , IL5 , and IL-13 [5]. IL-4 together with IL-13 causes isotype classswitching of B cells towards Immunoglobulin-E (IgE) synthesis, which can bind to high-affinity receptors on mast cells and basophils, and leads to subsequent activation of these cells. IL-5 activates eosinophils and attracts them to the lung, where they secrete numerous inflammatory cytokines and chemokines. IL-13 also directly affects the airway epithelium, including increases in goblet cell differentiation, activation of fibroblasts, and bronchial hyperresponsiveness [5-7]. These cytokines may also in turn affect the Th1/Th2 balance $[5,8]$. It has been acknowledged that two transcription factors, that is, T-bet and GATA-3, are responsible for Th1/Th2 balance. Further, GATA-3 and T-bet can be influenced by IL-12, IFN- $\gamma$, or IL-4 via the signal transducers and activators of transcription (STAT), that is, STAT4, STAT1, and STAT6, respectively [5].

Extractives from Astragalus, Panax ginseng, Saururus chinensis, Psoralea, and Ligustrazine [9] were reported a similar mechanism of decreasing the ratio of GATA3/T-bet expression level. Typically, Jin et al. [10] investigated the effects of the boiling water extract of Psoralea fructus (PF) and psoralen, an active ingredient of PF, on Th2 clone (D10.G.4.1) cells in vitro and in vivo, and interpreted their effect as suppressing GATA3 protein expression. Similarly, Chen et al. [11] found that a single compound, Bavachinin, isolated from PF decreased the GATA-3 function by reducing the stability of GATA-3 mRNA and further suggested that Bavachinin may suppress the binding or coactivating function but not expression of pSTAT6. In their further study [12], two new derivatives of Bavachinin with a better water solubility were investigated, and one of these two derivatives not only inhibited GATA-3 mRNA production but also increased T-bet mRNA production. However, clinical research for Psoralea fructus in treating asthma is lacking. Only few case reports [13] involving Psoralea fructus related recipe in Chinese can be found but provided limited evidence.

Efficacy on STAT6 was reported in extracts from Scutellaria baicalensis [14] and Cnidii monnieri [15]. Chiu et al. [15] explored the effects of Osthol (Cnidii monnieri fructus extract) on epithelial cells using human bronchial epithelial cells (BEAS-2B) in vitro. Their research demonstrated that Osthol suppressed IL-4-induced eotaxin (a key mediator in allergic diseases with eosinophilic infiltration) in epithelial cells via inhibition of STAT6 expression.

Besides, without further mechanism revealed, efficacy on Th1/Th2 cytokines was also observed in taraxasterol (isolated from Taraxacum officinale) [16], Duchesnea chrysantha ethanol extract [17], Echinacea purpurea complex [18], matrine (isolated from Sophora flavescens) [19], Zingiber officinale (both ethanol and aqueous extracts) [20], Actinidia polygama fructus extract [21], and formulas like Sam So Eum [22] and Qu Feng Xuan Bi [23].
2.2. Effect on MAPK and NF- $\kappa B$ Signaling Pathways. Mitogen-activated protein kinases (MAPKs), which comprise three major subgroups, that is, extracellular signalrelated kinase 1/2 (ERK1/2), p38, and c-Jun N-terminal kinase $1 / 2(\mathrm{JNK} 1 / 2)$, play critical roles in the activation of inflammatory cells [24]. Nuclear factor kappa B (NF- $\kappa$ B) is an important transcription factor involved in the expression of various proinflammatory genes. Increased activation of NF$\kappa \mathrm{B}$ has been observed in the lungs after allergen challenge and in airway epithelial cells and macrophages from asthmatic patients [25]. Many studies have reported that allergic asthma could be improved by regulating the activation of MAPK and NF- $\kappa$ B signaling pathways $[26,27]$.

Herbs that were extracted targeting on MAPKs include Scutellaria baicalensis [28, 29], Panax ginseng [30], Saururus chinensis [31], Artemisia annua [32], Magnoliae flos [33, 34], and Crocus sativus [35]. While NF- $\kappa$ B inhibitors can be found in Scutellaria baicalensis [36], Astragalus [37, 38], Saururus chinensis [31], Astilbe chinensis [39], Artemisia annua [32], and Garlic [40]. Although they performed similar mechanisms, minor differences could be noticed. Some extracts like dihydroartemisinin [32] (isolated from Artemisia annua) and meso-Dihydroguaiaretic acid [31] (isolated from Saururus chinensis) act as inhibitors of MAPKs and NF- $\kappa \mathrm{B}$ meanwhile, whereas some extracts isolated from the same herb may inhibit either MAPKs or NF- $\kappa$ B, respectively, for example, Oroxylin A [36] and Baicalin [28, 29] (both isolated from Scutellaria baicalensis). Details can be found in Table 1 .

\subsection{Targeting the Treg/Th17 Cells. T-regulatory cells (Tregs)} are a heterogeneous group of cells that play a central role in maintaining the homeostasis of pulmonary immunity by establishing immune tolerance to nonharmful antigens or suppressing effector $\mathrm{T}$ cell immunity. The specification of Treg subset is driven by transcription factor forkhead box P3 (Foxp3) [5, 75-78]. Th17 cells are key players in chronic lung inflammation, including asthma. Steroid-resistant asthma and neutrophil-mediated asthma have been proved to be related to Th17 cells. IL-17 also directly affects the airway smooth muscle by inducing allergen-induced airway hyperresponsiveness [79-82]. ROR $\gamma \mathrm{t}$ is found to be the transcription factor related to Th17, which is required to activate IL-17 production in Th17 cells [5]. Increased expressions of IL-17A and IL-17F have been shown in lung tissue of asthma patients [6]. Thus, herbal treatments targeting Foxp3 and ROR $\gamma$ t have been revealed gradually.

Extracts from Astragalus [46, 48], Panax ginseng [52], Crocus sativus [60], Ligustrazine [9], and Anoectochilus formosanus [64] were observed increasing Tregs and enhancing Foxp3 mRNA expression. In particular, ligustrazine, isolated from Ligustrazine (Chuan Qiong), was reported modulating the expression of not only T-bet/Gata-3 but also Foxp3/ROR $\gamma \mathrm{t}$ [9]. Ji et al. [9] noticed that ligustrazine reduced not only eosinophils but neutrophils in the BALF of asthmatic mouse model, implying that it could have potential for use in alleviation of neutrophilic asthma.

Besides, there were more studies about herbal treatments in other Th17-related inflammatory diseases, such 


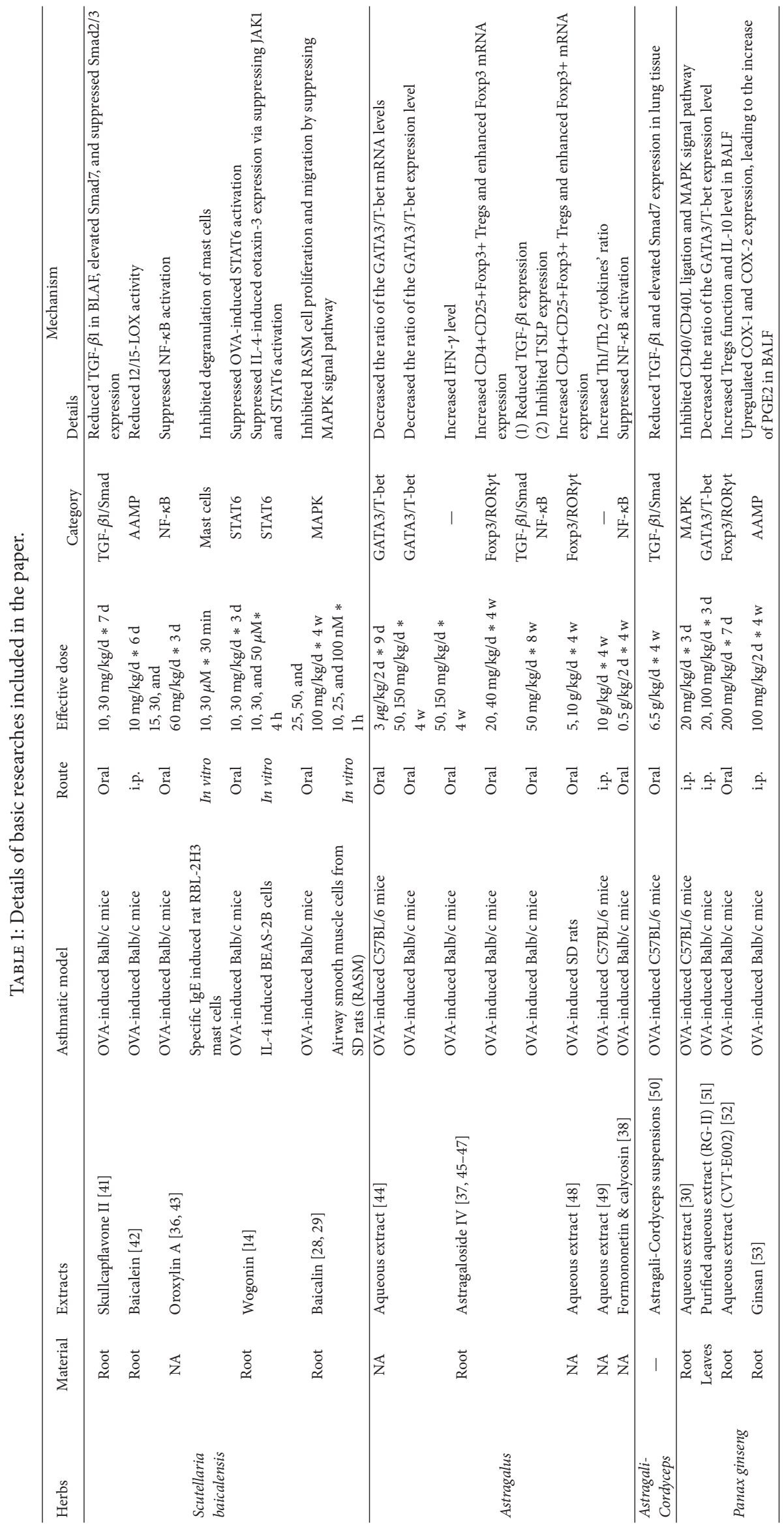




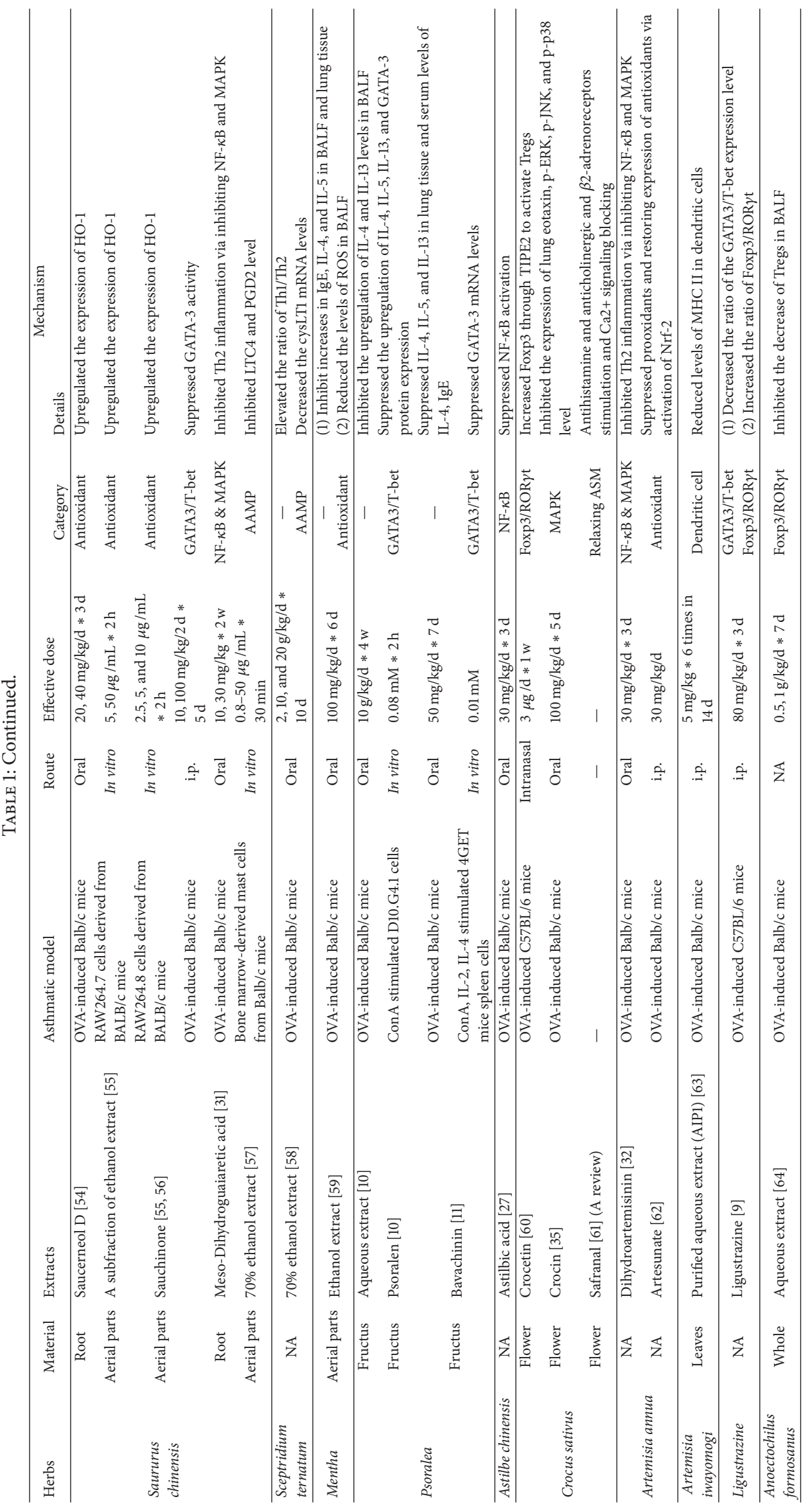




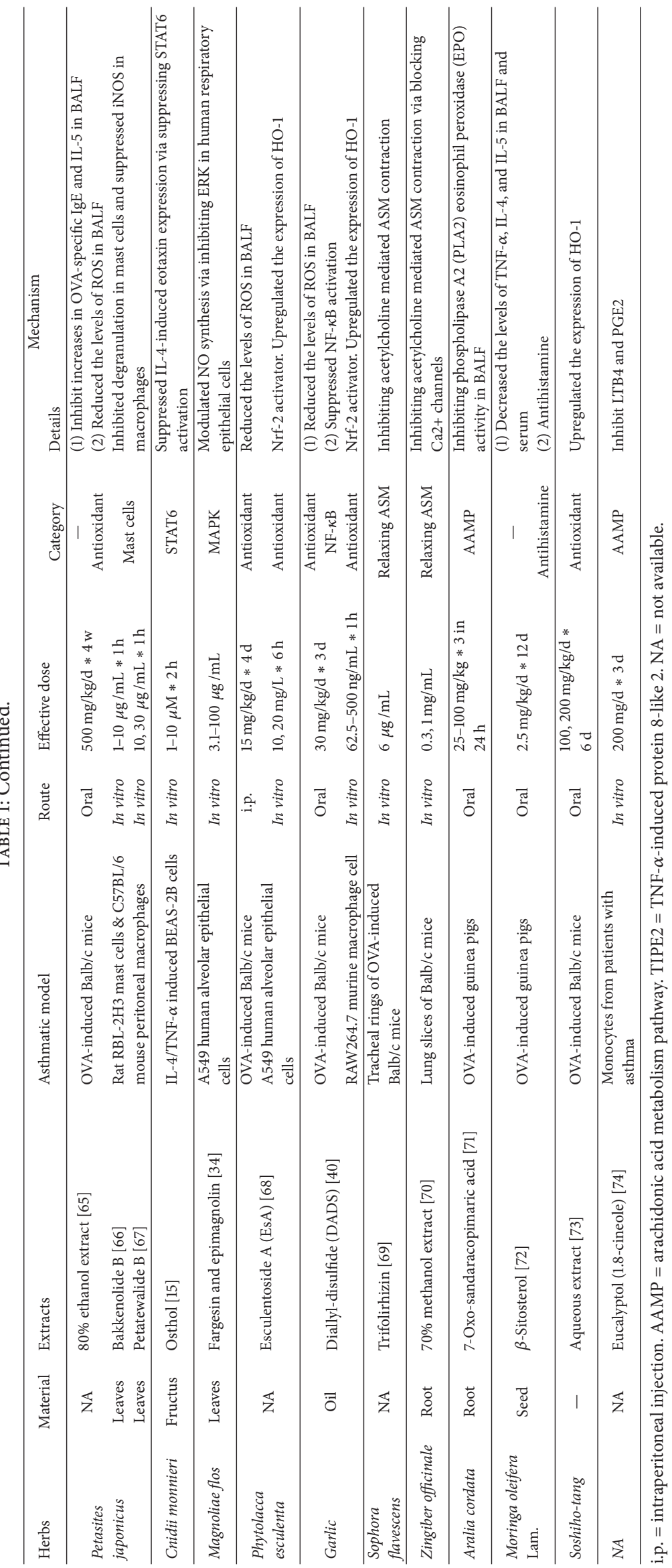


as Andrographis paniculata, Scutellaria baicalensis, Tripterygium wilfordii, and Wedelia chinensis [33, 83-85]. However, whether these herbs work similarly in asthma needs further investigations.

2.4. Effect on Lung Dendritic Cells (DCs). Dendritic Cells (DCs) participated not only in the differentiation of T helper cells but also in IL-12 production and CD8+ T cell stimulation via antigen uptake. Two subsets of blood DCs, that is, myeloid and plasmacytoid DCs, were identified based on the expression of CD11c [5]. Most CD11c+ myeloid DCs in the lung are immature, which express relatively low levels of major histocompatibility complex (MHC) class II, and have a high capacity of antigen uptake but poor T cell stimulating activity [5]. Thus, inhibiting functional differentiation of pulmonary immature DC to mature DC may be a strategy to restrict the activation of T cells.

Lee et al. [63] discussed the effect of Artemisia iwayomogi polysaccharide-1 (AIP1) on DC functions. They observed significantly reduced levels of MHC II in DCs of the AIP1 treated group, suggesting that AIP1 could reduce the expression of MHC II molecules on pulmonary DC. They also reported that AIP1 diminished the allergenic T cell stimulating ability of DCs derived from bone marrow in another study. These data suggested that AIP1 could inhibit functional differentiation of pulmonary DCs in vivo.

2.5. Effect on Mast Cell Degranulation. Mast cell degranulation, which can be triggered by antigen-mediated crosslinking of IgE bound to FcER1 surface receptors or changes in the surrounding local tissue environment, plays an important role in asthmatic response. As a result, many of the mediators that are stored or newly synthesized by the mast cells are released attracting leukocytes (eosinophils, basophils, Th2 lymphocytes, and neutrophils) to the inflammatory site and amplify the inflammatory response [86]. Hence, inhibiting mast cell degranulation will be helpful for asthma treating.

We gathered three extracts that associated with this process: Oroxylin A [43], Bakkenolide B [66], and Petatewalide B [67]. The first one is isolated from Scutellaria baicalensis while the next two are from Petasites japonicus. It is worth mentioning that both Bakkenolide B and Petatewalide B do not inhibit antigen-induced $\mathrm{Ca} 2+$ increases in mast cells, which suggested that Bakkenolide B/Petatewalide B induced inhibition of degranulation seems not to be mediated via the inhibition of $\mathrm{Ca} 2+$ channel or $\mathrm{Ca} 2+$ increase in mast cells. As for Oroxylin A, no detailed mechanisms were provided to expand the phenomenon of inhibiting mast cell degranulation. Further mechanistic investigations on these extracts are necessary.

2.6. Effect on Oxidative Stress. Oxidative stress plays an important role in the pathogenesis of most airway diseases, particularly when inflammation is prominent. Recently, heme oxygenase-1 (HO-1) was shown to be induced in the airways of patients with asthma. As a natural antioxidant defense, HO-1 exerts cytoprotective reactions against oxidative cell injury. Greater HO-1 expression may mitigate asthma symptoms and suppressed IL-13-induced goblet cell hyperplasia and MUC5AC production [87-89]. Hence, targeting on $\mathrm{HO}-1$ or its transcription factor nuclear factor E2-related factor $2(\mathrm{Nrf}-2)$ [90] is a considerable strategy for asthma control.

To date, a variety of HO-1 activator can be extracted from Saururus chinensis [54, 55], Phytolacca esculenta [68], Garlic [40], and soshiho-tang [73]. Among them, diallyl-disulfide (isolated from Garlic) [40] and esculentoside A (isolated from Phytolacca esculenta) [68] have been further proved as Nrf2 activators. Beyond these, artesunate from Artemisia annua was also observed suppressing prooxidants and restoring expression of antioxidants via activation of Nrf-2 [62].

There are also some studies that only showed a reduced level of oxidative stress marker reactive oxygen species (ROS) when extracts like ethanol extracts of Mentha [59] and Petasites japonicus [65] intervened. The mechanisms by which they reduce ROS level need further study.

2.7. Effect on Relaxing Airway Smooth Muscle. Airway contraction is an important feature of asthma, and recent strategies to relax airway smooth muscle include antihistamine and anticholinergic and $\beta 2$-adrenoreceptors stimulation and $\mathrm{Ca} 2+$ signaling blocking [61].

Mokhtari-Zaer et al. [61] summarized the Crocus sativus's (saffron's) effect on relaxing airway smooth muscle in a review. Aqueous-ethanolic extract of Crocus sativus and safranal were mentioned in their article and showed multiple effects including antihistamine, anticholinergic, and $\beta 2$ adrenoreceptors stimulation according to four published studies.

Yang et al. [69] identified that trifolirhizin, a flavonoid compound isolated from Sophora flavescens, was responsible for inhibiting acetylcholine induced airway smooth muscle (ASM) contraction independent of $\beta 2$-adrenoceptors.

Aqueous methanolic extract from Zingiber officinale (ginger) was also reported having effect on acetylcholine induced airway contraction. Ghayur et al. [70] indicated that its effects were associated with $\mathrm{Ca} 2+$ signaling, possibly via blocking $\mathrm{Ca} 2+$ channels on plasma membrane.

2.8. Effect on Airway Remodeling. It is believed that airway smooth muscle (ASM) cell proliferation and migration play important roles in airway remodeling. Both platelet-derived growth factor (PDGF) and transforming growth factor- $\beta$ (TGF- $\beta$ ) are reported to be related to airway remodeling [91]. Recently, TGF- $\beta 1 /$ Smad signal pathway was found to be one of the important mechanisms for signal conduction in asthma airway remodeling [92].

Astragaloside IV and Skullcapflavone II, extracts from Astragalus and Scutellaria baicalensis, respectively, were reported to attenuate the allergen-induced airway remodeling in mice, likely through inhibition of TGF- $\beta 1[37,41]$. Further research was performed by Jang et al. [41] and indicated that Skullcapflavone II elevated Smad7 and suppressed Smad2/3 expression, which was responsible for TGF$\beta 1$ inhibition. As for Astragalus, our group researched several formulas using Astragalus as key component acting on TGF- $\beta 1 /$ Smad signal pathway. The one Astragali-Cordyceps Mixtura [50] decreased TGF- $\beta 1$ expression and recovered Smad7 protein expression, and the other one Astragali radix 
Antiasthmatic Decoction (AAD) [93] was also found to improve the symptoms of allergic airway remodeling through inhibition of Th 2 cytokines and TGF- $\beta 1$. In a recent study, we also noticed that Suhuang antitussive capsule, a traditional Chinese medication, significantly attenuated the allergeninduced AHR, inflammation, and remodeling in mice, likely through inhibition of IL-13 and TGF- $\beta 1$ [94].

\subsection{Effect on the Arachidonic Acid Metabolism Pathway} $(A A M P)$. Arachidonic acid (AA) from the diet or after synthesis is stored in membrane phospholipids and is liberated under appropriate stimulatory conditions by the enzyme phospholipase A2 (PLA2). Arachidonic acid is then metabolized by three main classes of enzymes (cyclooxygenases (COX), lipoxygenases (LOX), and p450 epoxygenases) and all products of these three pathways like prostaglandin E2 (PGE2), prostaglandin D2 (PGD2), leukotrienes (LTs), and so forth are related to inflammatory and anaphylactic reaction. To be specific, PGE2 has been thought of as a potent proinflammatory mediator and has many beneficial functions in the lung tissues, such as the inhibition of inflammatory cell recruitment, reduction of leukotrienes and PGD2, and decrease of Th2 differentiation, thereby modulating inflammation and tissue repair. LTs (LTB4, LTC4, LTD4, etc.) are also thought to be important mediators of airway inflammation and airway obstruction in asthma. LTB4 can act as a neutrophil chemoattractant $[53,95,96]$. Thus, strategies targeting AA metabolism are effective in many inflammatory diseases.

Extracts from Scutellaria baicalensis [42], Panax ginseng [53], Saururus chinensis [57], Sceptridium ternatum [58], Aralia cordata [71], and eucalyptol (1.8-cineole) [74] have been found targeting different steps of the arachidonic acid metabolism pathway (AAMP). Details can be checked in Table 1.

Particularly, there are 4 herbs we would like to review individually as follows for their multiple function of antiasthma and popularity in basic researches.

Scutellaria baicalensis is a multifunctional traditional herb. Its extracts include Skullcapflavone II, Baicalein, Oroxylin A, wogonin, and Baicalin, which showed different but maybe cooperative functions in treating asthma. All of them have been proved in animal experiment or in vitro but not in human as mentioned before. And their results only showed simplex function on some cytokines or genes related to asthma. Whether they can benefit the whole interaction when asthma occurred is still unclear. For example, Jang et al.s experiment [41] indicated Skullcapflavone II's function on TGF- $\beta 1 /$ Smad signaling pathways. They observed a decreased level of TGF- $\beta 1$ in BALF, elevated Smad7 expression, and suppressed Smad2/3. However, as a pleiotropic and multifunctional growth factor, TGF- $\beta 1$ also exerts immunosuppressive effects on asthma progression, and therapies targeting on TGF- $\beta 1$ are still controversial, although it has been expatiated that TGF- $\beta 1$ is responsible for airway remodeling [97].

Another multifunctional herb with relative sufficient studies is Astragalus membranaceus. We have showed above that its extract has been reported acting on GATA3/T-bet and TGF- $\beta 1 /$ Smad and NF- $\kappa$ B signal pathway and Tregs within last few years. Among them, Astragaloside IV should be underlined here for the fact that it nearly performed all effects that Astragalus membranaceus possessed for treating asthma. However, it is a pity that although abundant studies were performed on Astragaloside IV, no clinical research on it is available to date.

Extracts (RG-II, CVT-E002, and ginsan) from Panax were also reported acting on different pathways involving GATA3/T-bet, MAPK, and Tregs and arachidonic acid metabolism pathway in animal models or in vitro. But whether these results can be applied to human is undetermined. It is worth mentioning that CVT-E002 has been well proved to reduce respiratory infection in patients with chronic lymphocytic leukemia and prevent acute respiratory illness in institutionalized older adults $[98,99]$. It may partly reflect its immunoregulation function on human. Researches on its efficacy on asthma patients are desired.

Saururus chinensis (SC) is an effective antioxidant. Three of its extracts (saucerneol D [54], a subfraction of its ethanol extract, and sauchinone [55]) showed similar effect of antioxidant through upregulating the expression of HO1. Among them sauchinone also suppressed GATA-3 activity [56]. Recently, a novel extract of SC named mesoDihydroguaiaretic acid was expounded by Song and his colleagues [31]. It exhibited a protective effect on allergic airway inflammation through inhibiting the Th2 inflammation attributed to its inhibition of the NF- $\kappa$ B and MAPK. Besides, its ethanol extract's action on arachidonic acid metabolism pathway was reported in this year [57]. Antiasthmatic effect for SC extracts is drawing wide attention in the last few years.

\section{Clinical Studies}

The clinical research of herbal therapy application in asthma is limited. Three meta-analysis or systematic reviews were published successively in 2007, 2008, and 2010 [100-102]. However, all of them could not get sufficient evidence to make recommendations for herbal treatment for asthma after comprehensive analysis of the efficacy and safety. Arnold et al. [100] evaluated effects of herbal medicines on lung function, reduction in use of corticosteroids, symptom scores, physical sign scores, use of reliever medications, health related quality of life, and adverse effects comparing with placebo, involving 21 different herbs or herbal formulas. Although a few of them had some effects on relief of symptoms, only boswellic acids (isolated from Boswellia) were reported to exert a relatively comprehensive effect on lung function, while the effects of other herbs were limited or inexact. In Clark et al's study [102], Mai-Men-Dong-Tang, Pycnogenol, Jia-Wei-SiJun-Zi-Tang, and Tylophora indica also showed potential to improve lung function. Moreover, 1.8-cineol (eucalyptol) was observed to reduce the use of corticosteroids and corticosteroid reduction tolerance $(<7.5 \mathrm{mg})$ in both of their studies $[100,102]$.

In the last five years, some new clinical trials on herbal treatment emerged but most of them still focus on the efficacy for patients using an intact traditional or modified formula. The application of monomer extracts in clinic usually acts as adjuvant of standard asthma therapy according to the 
recent studies. In a noncomparative, multicenter trial [103], 148 patients with mild asthma taking ICS received NDC-052 (an extract from Magnoliae flos) for eight weeks. Their results showed that add-on NDC-052 besides ICS therapy had benefits in both $\triangle$ PEFR and asthma symptoms. Last year, a review by Ammon [104] showed multiple effects of Boswellia serrata extracts on immune system modulation in basic research, including inhibiting activation of $\mathrm{NF} \kappa \mathrm{B}$, mast cell stabilisation, and antioxidant and inhibitory action on 5-LOX. However, related clinical research in the past five years can only be found for reducing the need for inhalation therapy with ICS + LABAs [105]. Although its significant effect on lung function had been analyzed by Arnold et al. as mentioned before [100], further research is still lacking.

Regarding intact traditional or modified formula for asthma reported recently, there are three types of research interests in the past five years.

First, herbal formula is singly used to relieve asthmatic symptom. These studies paid attention to the syndrome scores and frequency of asthma acute attack although these formulas may have limited efficacy on asthma process or lung function improvement. Geng et al. [106] performed a randomized, single-blind, placebo controlled trial (sample size $=60$ ) on intermittent asthmatic children aged 2 to 5 years. Their modified formula contained Radix Astragali Mongolici $10 \mathrm{~g}$, Rhizoma Polygonati Odorati $10 \mathrm{~g}$, Fructus Ligustri Lucidi 10 g, Fructus Psoraleae 10 g, Radix Pseudostellariae $3 \mathrm{~g}$, Fructus Schisandrae Chinensis $3 \mathrm{~g}$, Fructus Jujubae $10 \mathrm{~g}$, Concha Ostreae $10 \mathrm{~g}$, and Endoconcha Sepiellae $10 \mathrm{~g}$. Their results showed that the formula reduced the number of intermittent asthma attacks, decreased the syndrome scores, and reduced the airway resistance in the children. Homogeneously, another formula, "Zhisou Powder," is also observed to decrease the syndrome score and cough score of cough variant asthma, but it has no effect on airway responsiveness [107].

Second, maybe the most popular direction is usage of herbal formula as add-on therapy of standard medication to relieve asthmatic symptom and recurrence rate or strengthen the effect of standard medication. A randomized controlled research on 143 patients with moderate-severe asthma was performed by Tang and colleagues [108]. They applied their formula (containing 21 herbs and excipients) as add-on therapy of standard medication and showed decrease of exacerbation frequency and improvement of related syndrome scores, for example, asthma control test (ACT) score. Lin et al. [109] studied the effect of Astragalus plus hormone treatment in 90 asthmatic children. They showed that the effective rate of the Astragalus plus hormone group is significantly higher compared to using Astragalus or hormone only. The levels of PEFR and IFN- $\gamma$ significantly increased and IL- 4 obviously decreased in their effective cases. Besides, in another study, benefit of "chaipo granule" combined with routine treatment on refractory asthma was also discovered. "Chaipo granule" can act as a synergist of routine treatment according to their results [110]. Similar strengthening effect was also reported in the formula "Yupingfeng powder" [111].

Third, study in this research interests is according to a traditional administration method in China. Chinese called it
"Jiu" (moxibustion), which uses herbs burning at the related acupoint of patients. Peoples today modified the method and are using percutaneous absorption herbal patch to treat asthma. Typically, Chen et al. [112] compared their modified percutaneous absorption herbal patch with salmeterol fluticasone inhalation for asthma of paracmasis. Their results showed a significant improvement in clinical symptom scores.

\section{Conclusion Remarks}

After all the above, it can be noticed that herbal therapy mainly applied to mild asthma or acted as adjuvant of standard asthma therapy in clinical researches. It seems to become a trend. It might be a good way to use complementary and alternative medicine (CAM) to help control symptom and reduce the drug dose for those patients receiving standard medication, as it has been proved by several researches [100105, 108]. However, compared with the prosperous basic researches, clinical researches on asthma herbal therapy are relatively poor. It may be because many herbal extracts targeting on one or two factors of asthma may not be that meaningful when applied in clinic, as asthma is a disease with complex and multiple mechanisms. On the other hand, as the herbs were usually administrated as formula, simultaneously using extracts from different herbs with different mechanisms can also be a good research direction. It can be expected that they act synergetically and perform significant benefit on asthma when used simultaneously. Administrating purified extracts synergetically will have more precision than using intact formula directly.

Despite the remarkable achievements about herbal treatment for asthma during the past several years, several points should be addressed or be kept in mind in future studies. (1) Quality control of herbal medicines is always problematic, due to lack of standard procedures to make herb extractions, decoctions, or formula. Herbal patent drugs are generally of better quality, but there are few ones available for asthma researches. (2) Apparently, there is an urgent need for translational studies to transfer the current achievements on herbal medicines from animal works to clinical trials and finally to develop new clinical therapy. Current clinical trials for herbal medicines are limited, and thus more and large scaled, multicentre ones are extremely needed. Fortunately, well-designed and well-performed clinical trials for herbal medicines were appreciated by world-class journals [113], encouraging similar studies in asthma. (3) For clinical studies, the usage of herbal medicines for stable asthma is recommended. Asthma research in animal models usually cannot mimic the distinction between stable asthma and exacerbation. Herbal medicines might help to control stable asthma, while they may have limited effects during asthma exacerbations, since the herbs generally take longer time to exert therapeutic effects. (4) Clinical studies of herbal medicines in asthma control should target two major different goals. One is to take herbal medicines as a sole asthma control strategy, and the other is to use them as an add-on therapy for standard strategies, that is, to enhance the efficacy of or to reduce the usage of ICS. (5) Most of the current researches focused only on 
the eosinophilic phenotype of asthma, and few researches addressed other phenotypes like neutrophilic asthma, as the latter is usually severe asthma and is hard to control by current approaches. Thus, it is encouraged to conduct studies, both basic and clinical, to investigate the possible roles of herbal medicines in control of severe or neutrophilic asthma.

Nevertheless, herbal medicines for asthma hold out a cheerful prospect, which will eventually help to reduce the morbidity and mortality and increase the control levels of asthma worldwide.

\section{Competing Interests}

The authors declare that there is no conflict of interests regarding the publication of this paper.

\section{Acknowledgments}

This work was supported by the Key Project to Hua-Hao Shen (81130001) and the General Project to Zhi-Hua Chen (81370142) from NSFC, the Key Science-Technology Innovation Team of Zhejiang Province (2011R50016), and the program for a Key Site of the National Clinical Research Center for Respiratory Disease, Hangzhou, Zhejiang 310058, China.

\section{References}

[1] D. H. Broide, "Molecular and cellular mechanisms of allergic disease," Journal of Allergy and Clinical Immunology, vol. 108, no. 2, pp. S65-S71, 2001.

[2] Global Initiative for Asthma, "Global strategy for asthma management and prevention," 2015, http://ginasthma.org/.

[3] C. E. Ward and A. P. Baptist, "Characteristics of Complementary and Alternative Medicine (CAM) use among older adults with asthma," Journal of Asthma, vol. 53, no. 5, pp. 546-552, 2016.

[4] T.-P. Huang, P.-H. Liu, A. S.-Y. Lien, S.-L. Yang, H.-H. Chang, and H.-R. Yen, "Characteristics of traditional Chinese medicine use in children with asthma: a nationwide population-based study," Allergy, vol. 68, no. 12, pp. 1610-1613, 2013.

[5] D. K. Agrawal and Z. Shao, "Pathogenesis of allergic airway inflammation," Current Allergy and Asthma Reports, vol. 10, no. 1, pp. 39-48, 2010.

[6] K. F. Chung, "Targeting the interleukin pathway in the treatment of asthma," The Lancet, vol. 386, no. 9998, pp. 1086-1096, 2015.

[7] L. van Rijt, H. von Richthofen, and R. van Ree, “Type 2 innate lymphoid cells: at the cross-roads in allergic asthma," Seminars in Immunopathology, vol. 38, no. 4, pp. 483-496, 2016.

[8] P. Bégin and K. C. Nadeau, "Epigenetic regulation of asthma and allergic disease," Allergy, Asthma and Clinical Immunology, vol. 10, no. 1, article 27, 2014.

[9] N.-F. Ji, Y.-C. Xie, M.-S. Zhang et al., "Ligustrazine corrects Th1/Th2 and Treg/Th17 imbalance in a mouse asthma model," International Immunopharmacology, vol. 21, no. 1, pp. 76-81, 2014.

[10] H. Jin, L. Wang, C. Xu et al., "Effects of Psoraleae fructus and its major component psoralen on Th2 response in allergic asthma," American Journal of Chinese Medicine, vol. 42, no. 3, pp. 665678, 2014.
[11] X. Chen, T. Wen, J. Wei et al., "Treatment of allergic inflammation and hyperresponsiveness by a simple compound, Bavachinin, isolated from Chinese herbs," Cellular \& Molecular Immunology, vol. 10, no. 6, pp. 497-505, 2013.

[12] X. Chen, Y. Shen, Q. Liang et al., "Effect of Bavachinin and its derivatives on T cell differentiation," International Immunopharmacology, vol. 19, no. 2, pp. 399-404, 2014.

[13] Y.-B. Zhou, M. Wu, and J.-E. Yu, "Treatment of recurrent respiratory infection with Chinese drug therapy of Tonifying-Shen and solidifying superficiality-a clinical case report," Chinese Journal of Integrative Medicine, vol. 17, no. 10, pp. 786-788, 2011.

[14] E. K. Ryu, T.-H. Kim, E. J. Jang et al., "Wogonin, a plant flavone from Scutellariae radix, attenuated ovalbumin-induced airway inflammation in mouse model of asthma via the suppression of IL-4/STAT6 signaling," Journal of Clinical Biochemistry and Nutrition, vol. 57, no. 2, pp. 105-112, 2015.

[15] P.-R. Chiu, W.-T. Lee, Y.-T. Chu, M.-S. Lee, Y.-J. Jong, and C.H. Hung, "Effect of the Chinese herb extract osthol on IL-4induced eotaxin expression in BEAS-2B cells," Pediatrics and Neonatology, vol. 49, no. 4, pp. 135-140, 2008.

[16] X. Zhang, J. Liu, H. Xiong et al., "Effects of taraxasterol on ovalbumin-induced allergic asthma in mice," Journal of Ethnopharmacology, vol. 148, no. 3, pp. 787-793, 2013.

[17] E. J. Yang, J.-S. Lee, C.-Y. Yun et al., "Inhibitory effects of Duchesnea chrysantha extract on ovalbumin-induced lung inflammation in a mouse model of asthma," Journal of Ethnopharmacology, vol. 118, no. 1, pp. 102-107, 2008.

[18] M. Šutovská, P. Capek, I. Kazimierová et al., "Echinacea complex - chemical view and anti-asthmatic profile," Journal of Ethnopharmacology, vol. 175, pp. 163-171, 2015.

[19] W.-C. Huang, C.-C. Chan, S.-J. Wu et al., "Matrine attenuates allergic airway inflammation and eosinophil infiltration by suppressing eotaxin and Th2 cytokine production in asthmatic mice," Journal of Ethnopharmacology, vol. 151, no. 1, pp. 470-477, 2014.

[20] A. M. Khan, M. Shahzad, M. B. Raza Asim, M. Imran, and A. Shabbir, "Zingiber officinale ameliorates allergic asthma via suppression of Th2-mediated immune response," Pharmaceutical Biology, vol. 53, no. 3, pp. 359-367, 2015.

[21] Y.-C. Lee, S.-H. Kim, Y.-B. Seo, S.-S. Roh, and J.-C. Lee, "Inhibitory effects of Actinidia polygama extract and cyclosporine A on OVA-induced eosinophilia and bronchial hyperresponsiveness in a murine model of asthma," International Immunopharmacology, vol. 6, no. 4, pp. 703-713, 2006.

[22] S. J. Cho, H. W. Kim, B.-Y. Kim, and S. I. Cho, "Sam So Eum, a herb extract, as the remedy for allergen-induced asthma in mice," Pulmonary Pharmacology and Therapeutics, vol. 21, no. 3, pp. 578-583, 2008.

[23] K. Zhou, L. Liu, and S. Shi, "Qu Feng Xuan Bi Formula attenuates anaphylactic rhinitis-asthma symptoms via reducing EOS count and regulating T cell function in rat ARA models," Journal of Ethnopharmacology, vol. 152, no. 3, pp. 568-574, 2014.

[24] J. S. C. Arthur and S. C. Ley, "Mitogen-activated protein kinases in innate immunity," Nature Reviews Immunology, vol. 13, no. 9, pp. 679-692, 2013.

[25] D. Gras, P. Chanez, I. Vachier, A. Petit, and A. Bourdin, "Bronchial epithelium as a target for innovative treatments in asthma," Pharmacology and Therapeutics, vol. 140, no. 3, pp. 290-305, 2013.

[26] X. Ci, X. Chu, X. Xu, H. Li, and X. Deng, "Short-term roxithromycin treatment attenuates airway inflammation via 
MAPK/NF- $\kappa$ B activation in a mouse model of allergic asthma," Inflammation Research, vol. 61, no. 7, pp. 749-758, 2012.

[27] Y. Zhang, L.-O. Cardell, L. Edvinsson, and C.-B. Xu, "MAPK/ NF- $\kappa \mathrm{B}$-dependent upregulation of kinin receptors mediates airway hyperreactivity: a new perspective for the treatment," Pharmacological Research, vol. 71, pp. 9-18, 2013.

[28] G. Yang, J. Q. Li, J. P. Bo et al., "Baicalin inhibits PDGF-induced proliferation and migration of airway smooth muscle cells," International Journal of Clinical and Experimental Medicine, vol. 8, no. 11, pp. 20532-20539, 2015.

[29] J. Sun, L. L. Li, J. F. Wu et al., "Effects of baicalin on airway remodeling in asthmatic mice," Planta Medica, vol. 79, no. 3-4, pp. 199-206, 2013.

[30] D. Y. Kim and W. M. Yang, "Panax ginseng ameliorates airway inflammation in an ovalbumin-sensitized mouse allergic asthma model," Journal of Ethnopharmacology, vol. 136, no. 1, pp. 230-235, 2011.

[31] J.-W. Song, C.-S. Seo, E.-S. Cho et al., "Meso-Dihydroguaiaretic acid attenuates airway inflammation and mucus hypersecretion in an ovalbumin-induced murine model of asthma," International Immunopharmacology, vol. 31, pp. 239-247, 2016.

[32] M. Wei, X. Xie, X. Chu, X. Yang, M. Guan, and D. Wang, "Dihydroartemisinin suppresses ovalbumin-induced airway inflammation in a mouse allergic asthma model," Immunopharmacology and Immunotoxicology, vol. 35, no. 3, pp. 382-389, 2013.

[33] W. Kou, R. Sun, P. Wei et al., "Andrographolide suppresses IL-6/ Stat3 signaling in peripheral blood mononuclear cells from patients with chronic rhinosinusitis with nasal polyps," Inflammation, vol. 37, no. 5, pp. 1738-1743, 2014.

[34] J. A. Baek, Y. D. Lee, C. B. Lee et al., "Extracts of Magnoliae flos inhibit inducible nitric oxide synthase via ERK in human respiratory epithelial cells," Nitric Oxide, vol. 20, no. 2, pp. 122$128,2009$.

[35] Y. Xiong, J. Wang, H. Yu, X. Zhang, and C. Miao, "Anti-asthma potential of crocin and its effect on MAPK signaling pathway in a murine model of allergic airway disease," Immunopharmacology and Immunotoxicology, vol. 37, no. 3, pp. 236-243, 2015.

[36] D.-G. Zhou, B.-Z. Diao, W. Zhou, and J.-L. Feng, "Oroxylin A inhibits allergic airway inflammation in ovalbumin (OVA)induced asthma murine model," Inflammation, vol. 39, no. 2, pp. 867-872, 2016.

[37] Q. Du, X. Y. Gu, G. Z. Feng et al., "Effects of astragaloside IV on the expressions of transforming growth factor- $\beta 1$ and thymic stromal lymphopoietin in a murine model of asthma," Zhonghua Yi Xue Za Zhi, vol. 91, no. 44, pp. 3139-3142, 2011.

[38] Z.-C. Yang, Z.-H. Qu, M.-J. Yi et al., "Astragalus extract attenuates allergic airway inflammation and inhibits nuclear factor $\kappa \mathrm{b}$ expression in asthmatic mice," American Journal of the Medical Sciences, vol. 346, no. 5, pp. 390-395, 2013.

[39] J.-E. Yuk, M.-Y. Lee, O.-K. Kwon et al., "Effects of astilbic acid on airway hyperresponsiveness and inflammation in a mouse model of allergic asthma," International Immunopharmacology, vol. 11, no. 2, pp. 266-273, 2011.

[40] I.-S. Shin, J. Hong, C.-M. Jeon et al., "Diallyl-disulfide, an organosulfur compound of garlic, attenuates airway inflammation via activation of the Nrf-2/HO-1 pathway and NF-kappaB suppression," Food and Chemical Toxicology, vol. 62, pp. 506$513,2013$.

[41] H.-Y. Jang, K.-S. Ahn, M.-J. Park, O.-K. Kwon, H.-K. Lee, and S.R. Oh, "Skullcapflavone II inhibits ovalbumin-induced airway inflammation in a mouse model of asthma," International Immunopharmacology, vol. 12, no. 4, pp. 666-674, 2012.

[42] U. Mabalirajan, T. Ahmad, R. Rehman et al., "Baicalein reduces airway injury in allergen and IL-13 induced airway inflammation," PLoS ONE, vol. 8, no. 4, Article ID e62916, 2013.

[43] A. Lee, S. Kang, S. Park, J. Huang, and D. Im, "Anti-allergic effect of oroxylin a from oroxylum indicum using in vivo and in vitro experiments," Biomolecules \& Therapeutics, vol. 24, no. 3, pp. 283-290, 2016.

[44] S.-M. Chen, Y.-S. Tsai, S.-W. Lee et al., "Astragalus membranaceus modulates Th1/2 immune balance and activates PPAR $\gamma$ in a murine asthma model," Biochemistry and Cell Biology, vol. 92, no. 5, pp. 397-405, 2014.

[45] Y.-Y. Qiu, J.-X. Zhu, T. Bian et al., "Protective effects of astragaloside IV against ovalbumin-induced lung inflammation are regulated/mediated by T-bet/GATA-3," Pharmacology, vol. 94, no. 1-2, pp. 51-59, 2014.

[46] X. Huang, L. Tang, F. Wang, and G. Song, "Astragaloside IV attenuates allergic inflammation by regulation Th1/Th2 cytokine and enhancement $\mathrm{CD} 4^{+} \mathrm{CD} 25^{+}$Foxp3 $\mathrm{T}$ cells in ovalbumin-induced asthma," Immunobiology, vol. 219, no. 7, pp. 565-571, 2014.

[47] X. Yuan, S. Sun, S. Wang, and Y. Sun, "Effects of astragaloside IV on IFN-gamma level and prolonged airway dysfunction in a murine model of chronic asthma," Planta Medica, vol. 77, no. 4, pp. 328-333, 2011.

[48] H. Jin, Q. Luo, Y. Zheng et al., "CD $4^{+} \mathrm{CD} 25^{+}$Foxp $3^{+}$T cells contribute to the antiasthmatic effects of Astragalus membranaceus extract in a rat model of asthma," International Immunopharmacology, vol. 15, no. 1, pp. 42-49, 2013.

[49] H.-H. Shen, K. Wang, W. Li et al., "Astragalus membranaceus prevents airway hyperreactivity in mice related to Th2 response inhibition," Journal of Ethnopharmacology, vol. 116, no. 2, pp. 363-369, 2008.

[50] G.-X. Gao, Q.-M. Li, and H.-H. Shen, "Effect of AstragaliCordyceps Mixtura on TGF- $\beta$ /Smad signal pathway in the lung of asthma airway remodeling," Journal of Ethnopharmacology, vol. 125, no. 1, pp. 68-74, 2009.

[51] I. D. Jung, H. Y. Kim, J. W. Park et al., "RG-II from Panax ginseng C.A. Meyer suppresses asthmatic reaction," BMB Reports, vol. 45, no. 2, pp. 79-84, 2012.

[52] C. Ebeling, Y. Wu, C. Skappak, J. R. Gordon, R. Ilarraza, and D. J. Adamko, "Compound CVT-E002 attenuates allergen-induced airway inflammation and airway hyperresponsiveness, in vivo," Molecular Nutrition and Food Research, vol. 55, no. 12, pp. 19051908, 2011.

[53] Y.-J. Lim, H.-S. Na, Y.-S. Yun et al., "Suppressive effects of ginsan on the development of allergic reaction in murine asthmatic model," International Archives of Allergy and Immunology, vol. 150, no. 1, pp. 32-42, 2009.

[54] J.-Y. Jung, K.-Y. Lee, M.-Y. Lee, D. Jung, E.-S. Cho, and H.Y. Son, "Antioxidant and antiasthmatic effects of saucerneol $\mathrm{D}$ in a mouse model of airway inflammation," International Immunopharmacology, vol. 11, no. 6, pp. 698-705, 2011.

[55] X. Meng, I. Kim, Y. J. Jeong, Y. M. Cho, and S. C. Kang, "Anti-inflammatory effects of Saururus chinensis aerial parts in murine macrophages via induction of heme oxygenase-1," Experimental Biology and Medicine, vol. 241, no. 4, pp. 396-408, 2016.

[56] H. J. Min, H. Y. Won, Y. C. Kim et al., "Suppression of Th2driven, allergen-induced airway inflammation by sauchinone," 
Biochemical and Biophysical Research Communications, vol. 385, no. 2, pp. 204-209, 2009.

[57] E. Lee, K. Haa, J. M. Yook et al., "Anti-asthmatic activity of an ethanol extract from Saururus chinensis," Biological and Pharmaceutical Bulletin, vol. 29, no. 2, pp. 211-215, 2006.

[58] Y. Yuan, B. Yang, Z. Ye et al., "Sceptridium ternatum extract exerts antiasthmatic effects by regulating Th1/Th2 balance and the expression levels of leukotriene receptors in a mouse asthma model," Journal of Ethnopharmacology, vol. 149, no. 3, pp. 701706, 2013.

[59] M.-Y. Lee, J.-A. Lee, C.-S. Seo, H. Ha, N.-H. Lee, and H.-K. Shin, "Protective effects of mentha haplocalyx ethanol extract (MH) in a mouse model of allergic asthma," Phytotherapy Research, vol. 25, no. 6, pp. 863-869, 2011.

[60] J. Ding, J. Su, L. Zhang, and J. Ma, "Crocetin activates Foxp3 through TIPE2 in asthma-associated treg cells," Cellular Physiology and Biochemistry, vol. 37, no. 6, pp. 2425-2433, 2015.

[61] A. Mokhtari-Zaer, M. R. Khazdair, and M. H. Boskabady, "Smooth muscle relaxant activity of Crocus sativus (saffron) and its constituents: possible mechanisms," Avicenna Journal of Phytomedicine, vol. 5, no. 5, pp. 365-375, 2015.

[62] W. E. Ho, C. Cheng, H. Y. Peh et al., "Anti-malarial drug artesunate ameliorates oxidative lung damage in experimental allergic asthma," Free Radical Biology and Medicine, vol. 53, no. 3, pp. 498-507, 2012.

[63] J.-A. Lee, H.-N. Sung, C.-H. Jeon et al., "A carbohydrate fraction, AIP1 from Artemisia iwayomogi suppresses pulmonary eosinophilia and Th2-type cytokine production in an ovalbumin-induced allergic asthma. Down-regulation of TNF$\alpha$ expression in the lung," International Immunopharmacology, vol. 8, no. 1, pp. 117-125, 2008.

[64] C.-C. Hsieh, H.-B. Hsiao, and W.-C. Lin, "A standardized aqueous extract of Anoectochilus formosanus modulated airway hyperresponsiveness in an OVA-inhaled murine model," Phytomedicine, vol. 17, no. 8-9, pp. 557-562, 2010.

[65] J.-S. Lee, E. J. Yang, C.-Y. Yun, D.-H. Kim, and I. S. Kim, "Suppressive effect of Petasites japonicus extract on ovalbumininduced airway inflammation in an asthmatic mouse model," Journal of Ethnopharmacology, vol. 133, no. 2, pp. 551-557, 2011.

[66] K.-P. Lee, S. Kang, S.-J. Park, Y.-W. Choi, Y.-G. Lee, and D.-S. Im, "Anti-allergic and anti-inflammatory effects of bakkenolide B isolated from Petasites japonicus leaves," Journal of Ethnopharmacology, vol. 148, no. 3, pp. 890-894, 2013.

[67] Y.-W. Choi, K.-P. Lee, J.-M. Kim et al., "Petatewalide B, a novel compound from Petasites japonicus with anti-allergic activity," Journal of Ethnopharmacology, vol. 178, pp. 17-24, 2016.

[68] X. Ci, W. Zhong, H. Ren, Z. Wen, D. Li, and L. Peng, "Esculentoside $\mathrm{A}$ attenuates allergic airway inflammation via activation of the Nrf-2 pathway," International Archives of Allergy and Immunology, vol. 167, no. 4, pp. 280-290, 2015.

[69] N. Yang, B. Liang, K. Srivastava et al., “The Sophora flavescens flavonoid compound trifolirhizin inhibits acetylcholine induced airway smooth muscle contraction," Phytochemistry, vol. 95, pp. 259-267, 2013.

[70] M. N. Ghayur, A. H. Gilani, and L. J. Janssen, "Ginger attenuates acetylcholine-induced contraction and $\mathrm{Ca}^{2+}$ signalling in murine airway smooth muscle cells," Canadian Journal of Physiology and Pharmacology, vol. 86, no. 5, pp. 264-271, 2008.

[71] J. H. Cho, J. Y. Lee, S. S. Sim, W. K. Whang, and C. J. Kim, "Inhibitory effects of diterpene acids from root of Aralia cordata on IgE-mediated asthma in guinea pigs," Pulmonary Pharmacology and Therapeutics, vol. 23, no. 3, pp. 190-199, 2010.
[72] S. G. Mahajan and A. A. Mehta, "Suppression of ovalbumininduced Th2-driven airway inflammation by $\beta$-sitosterol in a guinea pig model of asthma," European Journal of Pharmacology, vol. 650, no. 1, pp. 458-464, 2011.

[73] W.-Y. Jeon, H.-K. Shin, I.-S. Shin, S. K. Kim, and M.-Y. Lee, "Soshiho-tang water extract inhibits ovalbumin-induced airway inflammation via the regulation of heme oxygenase-1," BMC Complementary and Alternative Medicine, vol. 15, no. 1, article 329, 2015.

[74] U. R. Juergens, M. Stöber, L. Schmidt-Schilling, T. Kleuver, and H. Vetter, "Antiinflammatory effects of euclyptol (1.8-cineole) in bronchial asthma: inhibition of arachidonic acid metabolism in human blood monocytes ex vivo," European Journal of Medical Research, vol. 3, no. 9, pp. 407-412, 1998.

[75] S. Sakaguchi, T. Yamaguchi, T. Nomura, and M. Ono, "Regulatory T cells and immune tolerance," Cell, vol. 133, no. 5, pp. 775-787, 2008.

[76] S. Z. Josefowicz, L.-F. Lu, and A. Y. Rudensky, "Regulatory T cells: mechanisms of differentiation and function," Annual Review of Immunology, vol. 30, pp. 531-564, 2012.

[77] N. Ohkura, Y. Kitagawa, and S. Sakaguchi, "Development and maintenance of regulatory T cells," Immunity, vol. 38, no. 3, pp. 414-423, 2013.

[78] F. Ramsdell and S. F. Ziegler, "FOXP3 and scurfy: how it all began," Nature Reviews Immunology, vol. 14, no. 5, pp. 343-349, 2014.

[79] L. McKinley, J. F. Alcorn, A. Peterson et al., "TH17 cells mediate steroid-resistant airway inflammation and airway hyperresponsiveness in mice," Journal of Immunology, vol. 181, no. 6, pp. 4089-4097, 2008.

[80] R. H. Wilson, G. S. Whitehead, H. Nakano, M. E. Free, J. K. Kolls, and D. N. Cook, "Allergic sensitization through the airway primes Thl7-dependent neutrophilia and airway hyperresponsiveness," American Journal of Respiratory and Critical Care Medicine, vol. 180, no. 8, pp. 720-730, 2009.

[81] J. F. Alcorn, C. R. Crowe, and J. K. Kolls, “TH17 cells in asthma and COPD," Annual Review of Physiology, vol. 72, pp. 495-516, 2010.

[82] M. Kudo, A. C. Melton, C. Chen et al., "IL-17A produced by $\alpha \beta$ T cells drives airway hyper-responsiveness in mice and enhances mouse and human airway smooth muscle contraction," Nature Medicine, vol. 18, no. 4, pp. 547-554, 2012.

[83] X. Yang, J. Yang, and H. Zou, "Baicalin inhibits IL-17-mediated joint inflammation in murine adjuvant-induced arthritis," Clinical and Developmental Immunology, vol. 2013, Article ID 268065, 8 pages, 2013.

[84] A.-P. Peng, X.-Y. Wang, and J.-H. Zhuang, "Triptolide inhibites Th17 cell differentiation via regulating cyclooxygenase-2/ prostaglandin E2 axis in synovial fibroblasts from rheumatoid arthritis," Zhongguo Zhong Yao Za Zhi, vol. 39, no. 3, pp. 536$539,2014$.

[85] Y.-T. Huang, C.-C. Wen, Y.-H. Chen et al., "Dietary uptake of Wedelia chinensis extract attenuates dextran sulfate sodiuminduced colitis in mice," PLoS ONE, vol. 8, no. 5, Article ID e64152, 2013.

[86] M. Krystel-Whittemore, K. N. Dileepan, and J. G. Wood, "Mast cell: a multi-functional master cell," Frontiers in Immunology, vol. 6, article 620, 2016.

[87] I. Horváth, L. E. Donnelly, A. Kiss, P. Paredi, S. A. Kharitonov, and P. J. Barnes, "Raised levels of exhaled carbon monoxide are associated with an increased expression of heme oxygenase-1 
in airway macrophages in asthma: a new marker of oxidative stress," Thorax, vol. 53, no. 8, pp. 668-672, 1998.

[88] S. Noel, J. Saams, M. J. C. Ong et al., "Opposing effects of nasal epithelial $\mathrm{NAD}(\mathrm{P}) \mathrm{H}$ dehydrogenase quinine 1 and heme oxygenase 1 expression on upper and lower airway symptoms in adolescents with asthma," Journal of Allergy and Clinical Immunology, vol. 128, no. 2, pp. 422-424, 2011.

[89] K. Mishina, M. Shinkai, T. Shimokawaji et al., "HO-1 inhibits IL-13-induced goblet cell hyperplasia associated with CLCA1 suppression in normal human bronchial epithelial cells," International Immunopharmacology, vol. 29, no. 2, pp. 448-453, 2015.

[90] M. Aparicio-Soto, M. Sánchez-Hidalgo, A. Cárdeno et al., "Dietary extra virgin olive oil attenuates kidney injury in pristane-induced SLE model via activation of $\mathrm{HO}-1 / \mathrm{Nrf}-2$ antioxidant pathway and suppression of JAK/STAT, NF- $\kappa$ B and MAPK activation," Journal of Nutritional Biochemistry, vol. 27, pp. 278-288, 2016.

[91] G. Yang, J.-Q. Li, J.-P. Bo et al., "Baicalin inhibits PDGF-induced proliferation and migration of airway smooth muscle cells," International Journal of Clinical and Experimental Medicine, vol. 8, no. 11, pp. 20532-20539, 2015.

[92] G.-X. Gao, Q.-M. Li, and H.-H. Shen, "Effect of AstragaliCordyceps Mixtura on TGF- $\beta /$ Smad signal pathway in the lung of asthma airway remodeling," Journal of Ethnopharmacology, vol. 125, no. 1, pp. 68-74, 2009.

[93] S. Xu, B.-P. Tian, L.-H. Zhang et al., "Prevention of allergic airway hyperresponsiveness and remodeling in mice by Astragaliradix Antiasthmatic decoction," BMC Complementary and Alternative Medicine, vol. 13, article 369, 2013.

[94] C. Zhang, L.-H. Zhang, Y.-F. Wu et al., "Suhuang antitussive capsule at lower doses attenuates airway hyperresponsiveness, inflammation, and remodeling in a murine model of chronic asthma," Scientific Reports, vol. 6, Article ID 21515, 2016.

[95] C. M. Yates, P. C. Calder, and G. Ed Rainger, "Pharmacology and therapeutics of omega-3 polyunsaturated fatty acids in chronic inflammatory disease," Pharmacology and Therapeutics, vol. 141, no. 3, pp. 272-282, 2014.

[96] T. S. Hallstrand and W. R. Henderson, "An update on the role of leukotrienes in asthma," Current Opinion in Allergy and Clinical Immunology, vol. 10, no. 1, pp. 60-66, 2010.

[97] M. Al-Alawi, T. Hassan, and S. H. Chotirmall, "Transforming growth factor $\beta$ and severe asthma: a perfect storm," Respiratory Medicine, vol. 108, no. 10, pp. 1409-1423, 2014.

[98] K. P. High, D. Case, D. Hurd et al., "A randomized, controlled trial of panax quinquefolius extract (CVT-E002) to reduce respiratory infection in patients with chronic lymphocytic leukemia," Journal of Supportive Oncology, vol. 10, no. 5, pp. 195201, 2012.

[99] J. E. McElhaney, S. Gravenstein, S. K. Cole et al., "A placebocontrolled trial of a proprietary extract of north american ginseng (CVT-E002) to prevent acute respiratory illness in institutionalized older adults," Journal of the American Geriatrics Society, vol. 52, no. 1, pp. 13-19, 2004.

[100] E. Arnold, C. E. Clark, T. J. Lasserson, and T. Wu, "Herbal interventions for chronic asthma in adults and children," Cochrane Database of Systematic Reviews, no. 1, Article ID CD005989, 2008.

[101] B. B. Singh, R. Khorsan, S. P. Vinjamury, C. Der-Martirosian, A. Kizhakkeveettil, and T. M. Anderson, "Herbal treatments of asthma: a systematic review," Journal of Asthma, vol. 44, no. 9, pp. 685-698, 2007.
[102] C. E. Clark, E. Arnold, T. J. Lasserson, and T. Wu, "Herbal interventions for chronic asthma in adults and children: a systematic review and meta-analysis," Primary Care Respiratory Journal, vol. 19, no. 4, pp. 307-314, 2010.

[103] C. S. Park, T.-B. Kim, J.-Y. Lee et al., "Effects of add-on therapy with NDC-052, an extract from Magnoliae flos, in adult asthmatic patients receiving inhaled corticosteroids," Korean Journal of Internal Medicine, vol. 27, no. 1, pp. 84-90, 2012.

[104] H. P. T. Ammon, "Modulation of the immune system by Boswellia serrata extracts and boswellic acids," Phytomedicine, vol. 17, no. 11, pp. 862-867, 2010.

[105] T. Ferrara, G. De Vincentiis, and F. Di Pierro, "Functional study on Boswellia phytosome as complementary intervention in asthmatic patients," European Review for Medical and Pharmacological Sciences, vol. 19, no. 19, pp. 3757-3762, 2015.

[106] Y. Geng, W. Wang, J. Zhang, S. Bi, H. Li, and M. Lin, "Effects of Traditional Chinese Medicine herbs for tonifying Qi and kidney, and replenishing spleen on intermittent asthma in children aged 2 to 5 years old," Journal of Traditional Chinese Medicine, vol. 36, no. 1, pp. 32-38, 2016.

[107] Q. Miao, P.-C. Wei, M.-R. Fan, and Y.-P. Zhang, "Clinical study on treatment of cough variant asthma by Chinese medicine," Chinese Journal of Integrative Medicine, vol. 19, no. 7, pp. 539545, 2013.

[108] B. Tang, K. Shi, X. Li et al., "Effects of 'Yang-warming and kidney essence-replenishing' herbal paste on cold-related asthma exacerbation," Journal of Traditional Chinese Medicine, vol. 33, no. 4, pp. 468-472, 2013.

[109] Y. Lin, B. Wang, and X.-Q. Luo, "Clinical study of astragalus's preventing the recurrence of asthma in children," Zhongguo Zhong Xi Yi Jie He Za Zhi, vol. 31, no. 8, pp. 1090-1092, 2011.

[110] C.-H. Wei, M.-C. Wen, and N. Yu, "Clinical effect of chaipo granule combined with routine treatment on refractory asthma," Zhongguo Zhong Xi Yi Jie He Za Zhi, vol. 31, no. 1, pp. 33-36, 2011.

[111] Y.-M. Li, Q. Liu, and X.-Y. Li, "New percutaneous absorption herbal patch for asthma of paracmasis and its effect on the relative transcription factors of patients," Zhongguo Zhen Jiu, vol. 32, no. 5, pp. 459-463, 2012.

[112] X. H. Chen, H. J. Li, P. H. Zhang, H. H. Zhang, and H. Y. Guo, "Treating chronic persistent bronchial asthma children with abnormal myocardial enzyme spectrum by Yupingfeng powder: an efficacy observation," Zhongguo Zhong Xi Yi Jie He Za Zhi, vol. 34, no. 5, pp. 518-521, 2014.

[113] C. Wang, B. Cao, Q.-Q. Liu et al., "Oseltamivir compared with the Chinese traditional therapy maxingshigan-yinqiaosan in the treatment of H1N1 influenza: a randomized trial," Annals of Internal Medicine, vol. 155, no. 4, pp. 217-226, 2011. 


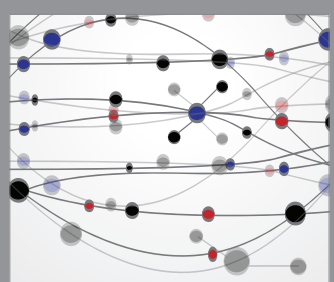

The Scientific World Journal
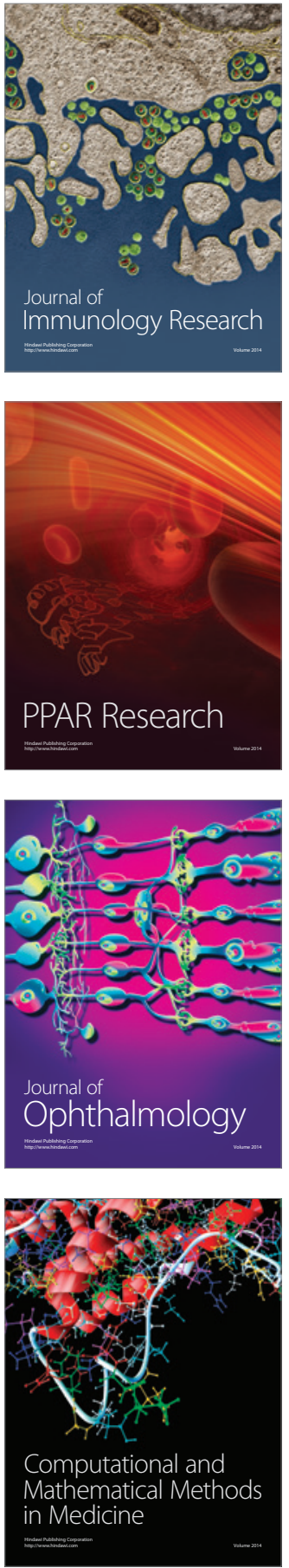

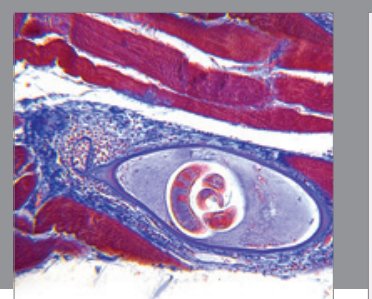

Gastroenterology Research and Practice

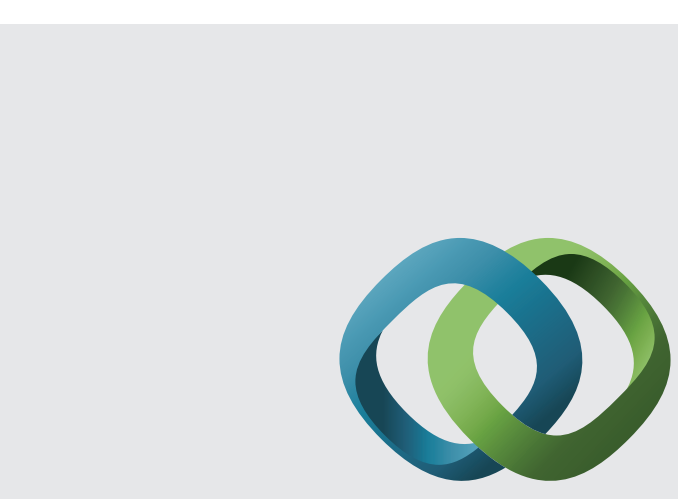

\section{Hindawi}

Submit your manuscripts at

http://www.hindawi.com
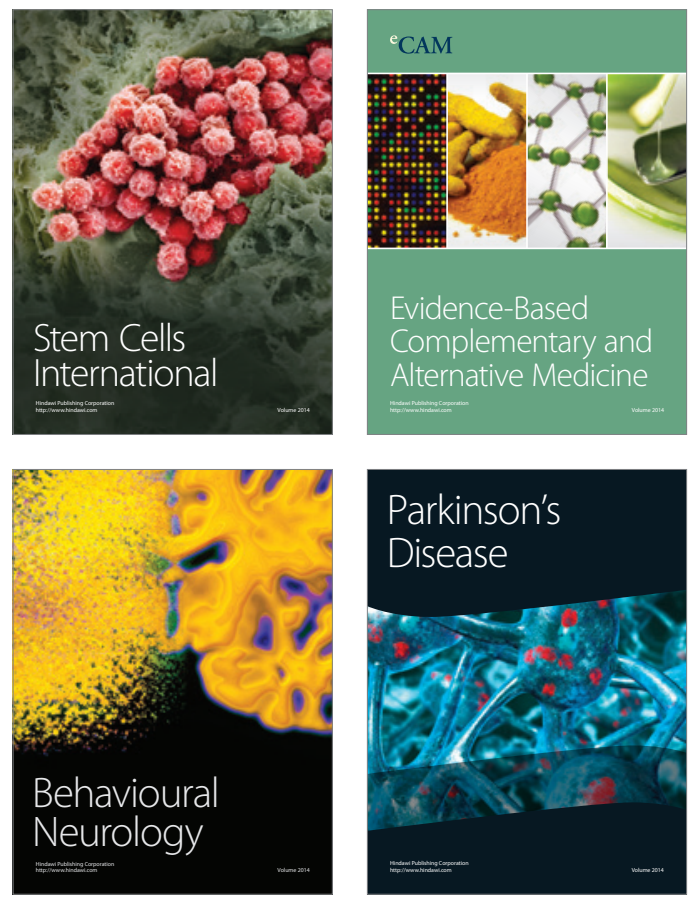
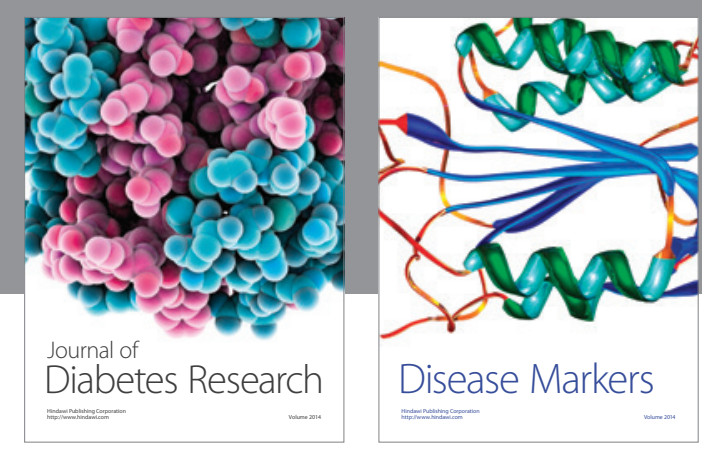

Disease Markers
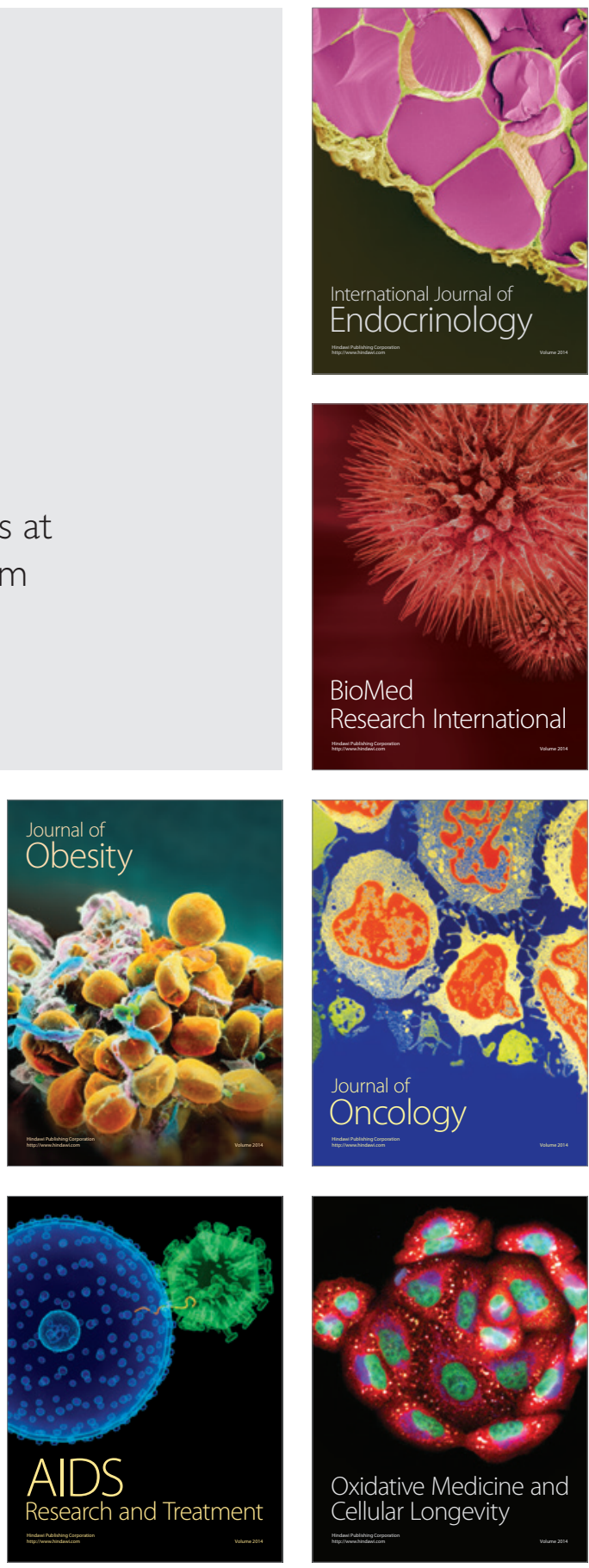